\title{
Measuring resilience is not enough; we must apply the research. Researchers and practitioners need a common language to make this happen.
}

\author{
Douglas M. Glandon
}

\begin{abstract}
This article is contributed by a practitioner in the area of country-level health systems strengthening who also has a background in resilience research. The intent of the article is to offer constructive reflection on the disconnect between the insights of resilience research and the application of those insights through development assistance. The primary reason for the existence of this communication block is that resilience research findings are not often translated in a format that is useful to those implementing resilience promotion projects. As a result, implementers do not usually review relevant research to guide their interventions. Resilience researchers and practitioners need a common language, one that arises from effective community engagement.
\end{abstract}

Key Words: community resilience; development assistance; research to action

\section{RESILIENCE IS EXPERIENCED AS A SOCIAL NARRATIVE, NOT AS A SET OF NUMBERS}

Although details vary from place to place, wherever you travel in the world, sooner or later you are likely to hear a story about resilience. Whether it is "bouncing back" from adversity or "bouncing forward" to a new normal that is enhanced in some way relative to the time before a traumatic event, examples of resilience can be found everywhere, from individuals and households to communities, organizations, and governments.

Some researchers have characterized resilience by focusing on the absence of a particular pathology, such as post-traumatic stress disorder, as noted by Almedom and Glandon (2007). Other researchers have explored resilience as a personality trait, or as a quantified adjustment in a group of people after a "potentially traumatic event". The adjustment would usually be compared to that of another group that experienced the same event exposure but had a different "adjustment" score (Bonanno 2012).

It is worth noting that many definitions of resilience, such as those listed above, are closely linked to a specific research methodology. This is convenient from a research perspective but may limit understanding of the particular resilience characteristics of the communities being studied. A broader, more holistic definition of resilience - and the one adopted for this article - is proposed by Almedom and Tumwine (2008):

\begin{abstract}
... resilience is defined as the capacity of individuals, families, communities, systems, and institutions to anticipate, withstand andlor judiciously engage with catastrophic events andlor experiences; actively making meaning with the goal of maintaining normal function without fundamental loss of identity.
\end{abstract}

This definition emphasizes the need to understand the catastrophic event from the perspective of members of the affected community, especially in terms of people's experiences relating to meaning and identity. This information is likely to come in the form of a story or narrative that has meaning to the community rather than through a specific analytical or conceptual lens.

Following are several examples of community resilience that were verbally relayed to me as part of my work in providing technical assistance for global development projects. These case examples were not investigated within any specific analytical framework The point here is that they are all conceptually consistent with the definition of resilience offered by Almedom and Tumwinethat is, each describes experiences of a community that actively responded to an adverse event, and essentially maintained normal functioning and, ostensibly, their collective identity.

\section{Benin}

To avoid being captured and sold into slavery by the Fon ethnic group of the Dahomey Kingdom in the 17th century, the Tofinu tribe literally moved their entire village into a lake. According to the guide who poled our pirogue through the village, the Tofinu knew that the Fon belief system prevented them from attacking them in a body of water so they begin building their homes, and eventually stores, schools, clinics, a church, etc., in Lake Nokoué. In other words, their thoughtful reflection on the threat facing them and their collective willingness to adapt to a totally different way of life is what allowed them to survive. The village, which still exists today and is on the tentative list for UNESCO World Heritage Sites, was named Ganvié, which in the Tofinu language roughly translates to "saved community".

\section{Senegal}

The population in the southern region of Senegal known as the Casamance has been living through a low-level civil war for three decades, experiencing periodic bursts of violence from the ongoing conflict between the local separatist movement and the national government in Dakar. Yet while the media tend to fixate on the turmoil and unrest, when I visited the Casamance shortly after the breakdown of negotiations with the Senegalese government in early 2005 I saw armed soldiers smiling and joking with each other amidst an otherwise typical backdrop of Senegalese village and town life. A local man from the Diola ethnic group of the Casamance explained that while the people of the region had suffered, the conflict actually reinforced their cultural identity as a distinct group with an egalitarian structure and a sense of pride in resisting centralized authority, which is a narrative extending back to the time of French colonial rule.

\section{Tanzania}

Once having spanned most of the Great Rift Valley in East Africa, the pastoralist Maasai are now having to adapt to decreasing access to land due to environmental preservation, tourism, or other pressures, leading to frequent characterizations of the 
Maasai as a dying culture or as a tribe struggling to survive. Yet, while working on a research project in Dar es Salaam from June to August 2006, I also saw another side of the story, in the forms of traditionally dressed Maasai men with machetes and cattleherding staffs amidst the rush-hour pedestrian traffic of jeans, tshirts, business suits, and briefcases - walking to work. The Maasai seem to have gained an impressive market share in the security guard business, leveraging their historical reputation as skilled warriors. While it is certainly no justification for forced migration, the ability of the Maasai to adapt to an urban livelihood while retaining their distinctive identity also makes it difficult to fully justify the "dying culture" narrative.

\section{Haiti}

Traditional religious beliefs were suppressed when Haiti became a French slave colony in the $18^{\text {th }}$ century and Haitians were forced to convert to Christianity. In response, many Haitians nominally accepted the new faith to avoid persecution, simultaneously renaming traditional deities as Christian figures, including God and the saints. In 2007 I had the opportunity to see the modernday expression of this religious syncretism while visiting Plaine du Nord with an undergraduate student research team during the Catholic celebration in honor of St. Jacques - who also happens to symbolize the voodoo spirit Ogoun. Inside the church a wallto-wall crowd sang hymns and listened to passages from the Bible during Mass. At the same time, just outside the church doors and extending through the streets was a crowd of voodoo adherents with thousands of lit candles, chanting, drumming, dancing, and performing various rituals including animal sacrifices and bathing in a mud pool in the center of town. The Catholic practices and icons that were once imposed upon the country have now become a source of prayer and celebration for those still adhering to their traditional beliefs.

\section{Fiji}

To deal with and prevent shortages of fish as a food source, chiefs in Fijian coastal villages traditionally established periodic "taboos", or bans, on fishing in certain areas to replenish the fisheries. Several local fishermen explained to me that this approach worked well in the past when the fishing vessels were small, stayed closer to shore, and were piloted by other islanders. With the advent of modern commercial fishing, often done in deeper waters by foreign vessels, the traditional taboos became markedly less effective and now the only feasible means of regulating fishing is through maritime policing by the national government. However, rather than managing this effort independently, the national government chose to integrate the traditional practice of taboo into the effort, thereby gaining widespread support and collaboration from communities across the country. While fish shortages are an ongoing challenge in Fiji, this method has already shown positive results in some parts of the country (Corcoran and Hughes 2012).

\section{RESEARCH SHOULD HELP TRANSLATE COMMUNITY NARRATIVES INTO INSIGHTS}

Human resilience is intrinsically linked to the social, natural, and built environments in which people live. Narratives provide a contextual richness that is critical for investigating the phenomenon. A clear analytical framework can sort through the details of these stories to derive insights that may help promote resilience, whether within the same community or elsewhere.
For instance, if we refer to a community's resilience, are we talking about its ability to maintain certain attributes during times of adversity, such as a sense of cultural identity, psychosocial wellbeing, access to food, or something else? Or are we referring to its ability to modify some characteristics in order to adapt to a changing environment or circumstances, such as moving to a new location or reinventing a belief system?

Due to the wide variety of interpretations of resilience, the appropriate analytical framework should clarify what is actually meant by "resilience" - including resilience by whom or of what - and how it may be enhanced. The framework has value when it helps break down and analyze a social narrative of resilience, much as a literary critic might assess the key elements of a novel. In the context of human resilience, if an adverse event is the conflict, a useful analytical framework helps us investigate the factors that influence the characters' abilities to cope or adapt.

While some resilience-promoting or "salutogenic" traits or characteristics (Antonovsky 1996), such as genetic traits, are more or less fixed and cannot be changed, others, such as child-rearing practices, social support, cognitive interventions, coping selfefficacy (Southwick 2012), and social cohesion or connection (Zraly and Nyirazinyoye 2010), may have prescriptive value for shaping interventions and possibly public education.

It is this latter category, of what could be termed malleable or transferable factors, that captures the interest of practitioners in the health and development community. By understanding salient factors that promote resilience in a particular context, we gain ideas about which ones might help promote resilience in other groups, locations, circumstances, or adversities. If, for instance, we want to examine the examples of community resilience narratives mentioned above to find insights that might be relevant elsewhere, selecting a suitable analytical framework is a critical first step.

One useful construct is the notion of "resilience pivots" that was introduced by Rotarangi and Stephenson (2014) to highlight elements of a particular community or group that remain constant through an adverse event. If we were to apply this lens to the Senegal example, we could investigate whether the continuity, and perhaps even reinforcement, of the Diola cultural identity as an independent, egalitarian community in the Casamance region helped that population cope with the longterm separatist conflict. Similarly, the resilience pivot concept may also help describe how the incorporation of the traditional cultural practice of taboo in temporarily banning fishing in certain areas of Fiji is currently helping the country respond to and prevent the depletion of its marine resources from overfishing.

Folke et al. (2010) articulated how "transformational change" at a local or specific level can contribute to resilience at a larger scale or in a broader context. Looking at the resilience narrative from Benin, this view might support the idea that the decision of the Tofinu to move their home into a lake was a transformational change that ultimately allowed them to survive as a group. Similarly the Haitians completely redefined their religious icons during the French colonial period in order to retain their ability to openly practice their faith, while an increasing number of Maasai pastoralists reinvented their livelihood from herding 
livestock in the countryside to guarding homes and offices in a major urban center in order to continue to survive and provide for their families in a changing environment.

In each example we see a glimpse of how the right analytical framework and research questions may help guide practitioners in building resilience, especially when preparing for similar types of adverse events. The question is whether the insights from this type of analytical research can be effectively applied to strengthen resilience in individuals, communities, and populations. If so, the magnitude of the potential benefits creates an ethical imperative to do so. In this respect a quote from Leonardo DaVinci is fitting: "I have been impressed with the urgency of doing. Knowing is not enough; we must apply. Being willing is not enough; we must do" (Suh 2005).

\section{OPPORTUNITIES TO APPLY ANALYTICAL RESILIENCE RESEARCH ARE GROWING GLOBALLY}

It is encouraging to see that many governments and organizations have taken such an interest in resilience in recent years and have raised its priority on the social agenda, both in terms of domestic efforts and development aid for other countries.

This increased focus on resilience is especially visible in initiatives to help communities prepare for natural disasters and climate change. A Google search in August 2014 with depersonalized results for the words "resilience" plus the name of each of the countries listed above-one at a time-yielded references to climate- or disaster-related initiatives in at least eight out of the top ten search results for each country. For Senegal and Fiji, it was all of the top ten search results.

In monetary terms, climate-change-related initiatives in these same five countries account for nearly US\$300 million in approved development assistance funds since 2003. This is according to the database compiled by Climate Funds Update (http://www.climatefundsupdate.org), a joint initiative of the Overseas Development Institute and the Heinrich Böll Foundation, two independent think tanks based in the UK and Germany, respectively. Of note, all of the associated funding sources list resilience promotion as a key objective or priority on their respective websites.

According to the same database, the top ten country funding sources have collectively invested nearly US\$31 billion on climate change worldwide through development assistance initiatives since 2003 - and again, each one of the listed funding sources includes explicit references to resilience promotion on their websites.

Although these projects and investments represent only a subset of the myriad initiatives worldwide for promoting resilience as part of efforts to help communities and societies adapt to climate change, there are several valuable takeaway points, including: (1) climate change adaptation is a priority for many government and health and social development organizations; (2) resilience is increasingly seen as part and parcel of climate change adaptation efforts; and (3) lots of time, money, and labor are being invested in promoting resilience globally.

Furthermore, the general consensus among the scientific community that there will be a long-term gradual increase in at least some types of extreme weather events (Alley et al. 2007) is a strong indication that these types of resilience promotion efforts will continue and possibly increase into the foreseeable future.

\section{BOTH RESEARCHERS AND PRACTITIONERS HAVE ROLES TO PLAY IN BRIDGING THE GAP BETWEEN THEORY AND PRACTICE}

Given the substantial financial outlays represented by many of these efforts to strengthen resilience, naturally the funding institutions and agencies will invest considerable time and energy into careful, thoughtful planning and into developing appropriate mechanisms to monitor implementation progress. Implementers of resilience-promotion projects and programs will pay close attention to the level of quality and completion of planned infrastructure, the average increases in income among local poor, and the square kilometers of restored mangroves, and other key performance indicators, as they should. Some initiatives may even estimate the expected benefits in terms of helping communities cope with severe weather events or other effects of climate change. Whether or not these are appropriate or meaningful measures of resilience is less clear.

This is where analytical resilience research has a key role to play. To start, a review of relevant research articles and case studies may help practitioners who implement resilience programs to clarify their own definition of resilience and to identify examples of factors that have been demonstrated to promote resilience in similar communities or circumstances. Even taking the first step of translating resilience as an abstract concept into a specific, measurable framework with concrete examples may yield valuable insights for designing and implementing a project or program. Similarly, practitioners may benefit from existing evidence-based tools, such as those listed on the Resilience Alliance website (http://www.resalliance.org), when thinking about how to practically assess the resilience of social-ecological systems and develop strategies to enhance it.

Thoughtful community engagement is also critical to ensuring that the planned resilience initiatives complement and do not undermine pre-existing preferences, norms, and behaviors. Local residents understand how their neighbors think and behave in a way that could potentially take outsiders years to learn. Accessing that knowledge and enlisting the support of key community stakeholders is especially important for initiatives addressing climate change, since the proposed changes are often immediate while the anticipated consequences may be far into the future. Also, communities may have different views about which factors will be most important for strengthening their own resilience. In some cases, they may agree that what is needed most are more retaining walls or restoration of coastal mangroves, but in other cases it might be something completely different.

Yet despite the potential value of drawing from the available research and resources and seeking substantive input from communities to design and implement these initiatives, these steps seem to be frequently omitted, or addressed only perfunctorily. Because a large portion of development assistance funding is delivered through 2-to-5-year projects with predetermined objectives and deliverables, there may be insufficient time or insufficient contract flexibility for implementing agencies to work with communities to develop a shared framework for assessing and building resilience. Although "local stakeholder engagement" or the equivalent is almost guaranteed to be included as a contract 
requirement for many of these projects, the timelines and pressure to commence implementation as soon as possible mean that the de facto intent of this step is often to get endorsement or "buyin" from the appropriate local leaders. Hiring local staff to lead or guide project implementation can ameliorate, but not eliminate, these limitations.

The major risk of this type of superficial embrace of resilience as a concept is that we may end up with well-funded and wellintentioned initiatives that ultimately miss their mark because they lack a coherent, evidence-based design or are out of step with local customs and context. As Strauch et al. (2008) note, for instance, one critical limitation of many initiatives to enhance resilience in sub-Saharan Africa through water-related infrastructure is that they tend to focus on large-scale, one-off projects that fail to take into account the key "drivers of change" in social-ecological systems, including the ecosystem, people and technology, local knowledge, and property rights.

\section{INCREASING THE PRACTICAL IMPACTS OF RESILIENCE RESEARCH DOES NOT NEED TO BE COMPLICATED}

The key question is how we can translate insights from resilience research into proactive efforts led by communities to enhance resilience-promoting factors or characteristics. There will likely never be a single, sure-fire approach, but acknowledging that this is important would be a start. There is room for improvement within both the researcher and practitioner communities.

Although some researchers' primary objective may be to contribute to the academic body of knowledge on resilience, a worthy secondary objective would be to help guide efforts to translate that knowledge into actions that improve people's lives. If practitioners without a research background are to draw meaningful insights from academic articles about resilience, researchers may want to comment briefly on some of the potential implications of their findings in terms of how they might be applied in human communities. A good example of this is the work done by Brian Walker and David Salt in their books Resilience Thinking (2006) and Resilience Practice (2012), which provide practical guidance on how to understand and apply concepts of social-ecological resilience in real-world settings. It would also be useful to apply this type of approach to human resilience, using examples like the study by Almedom et al. (2007, as cited in Walker and Salt 2012) on the psychosocial transition in post-war Eritrea, which is briefly referenced in the latter book.

On the implementation side, funders of development projects have a key role to play. Beginning with the initial design, development assistance contracts that seek to enhance human resilience could recommend or require the implementer to review the relevant resilience literature or resources and identify any analytical frameworks or findings that may be useful. For example, a project team focusing on natural disaster resilience in the South Pacific may, as a result of reviewing the case study compiled by Rumbach and Foley (2014) about the 2009 tsunami in American Samoa, think more carefully about how to most effectively engage indigenous institutions through a national emergency response plan. The Workbook for Practitioners prepared by the Gunderson et al. (2010), while not designed for disaster preparedness per se, provides an easy-to-use worksheet for stakeholder mapping of local formal and informal institutions.
Relatedly, funders of resilience projects would do well to allow for an emergent contract design in which some of the specific objectives and approaches are initially kept broad so they can be refined through consultation with the relevant communities. While the funder will often pay for monitoring and evaluation personnel to track implementation progress and estimate the impact attributable specifically to the project investment, this information may be of little value to the local community and will quickly lose relevance once the project has been completed. There is also a need for projects to invest time, money, and personnel into engaging with relevant local institutions, such as ministries of health, universities, or other organizations, to develop monitoring and evaluation mechanisms that are meaningful and useful for them. As Walker and Salt point out (2012:53), "resilience practice is not so much about producing a single 'best' system description as it is about creating a process whereby the system description is constantly revisited, reiterated, and fed into adaptive management."

\section{THE NEED FOR APPLIED RESILIENCE RESEARCH WILL CONTINUE TO GROW}

As global interest in resilience continues to grow, whether related to climate change adaptation or other events, there will be increasing demand to translate what we know about resilience into practical action in order to strengthen it. Disaster relief and humanitarian response efforts will continue to include more language about resilience; in some cases, project funding proposals may even require it. As this happens, it will be important for practitioners to make sure "resilience" is not just a buzzword referenced in purpose statements and project plans, but a holistic view of how communities respond to adversity. Some interventions designed to enhance communities' ability to cope with extreme weather events may involve changes that are easy to observe, but the psychosocial and social-ecological factors should not be overlooked. The only way to make sure this happens is to actively engage local communities, not just through perfunctory consultations or buy-in from key leaders at the beginning, but throughout planning, implementation, and assessment. Insights from the literature on community resilience and available resources, such as those compiled by the Resilience Alliance, can help practitioners think critically and strategically about how to do this. Although these changes may in some cases require more time, effort, and flexibility in development assistance contracts, it is the only way to ensure that these resilience-promotion efforts actually benefit the communities they affect and that those benefits last beyond the duration of the initiative. A project may last 2 to 5 years; all signs point to climate change lasting much longer.

Responses to this article can be read online at: http://www.ecologyandsociety.org/issues/responses. $\mathrm{php} / 7576$

\section{LITERATURE CITED}

Alley, R. B. et al. 2007. Summary for policymakers. Pages 1-18 in Solomon, S., D. Qin, M. Manning, Z. Chen, M. Marquis, K. B. Averyt, M. Tignor, and H. L. Miller (editors). Climate change 2007: the physical science basis. Contribution of Working Group I 
to the Fourth Assessment Report of the Intergovernmental Panel on Climate Change. Cambridge University Press, Cambridge, UK and New York, New York, USA.

Almedom, A. M., and D. M. Glandon. 2007. Resilience is not the absence of PTSD any more than health is the absence of disease. Journal of Loss and Trauma: International Perspectives on Stress \& Coping 12(2):127-143. http://dx.doi.org/10.1080/15325020600945962

Almedom, A. M., and J. K. Tumwine. 2008. Resilience to disasters: a paradigm shift from vulnerability to strength. African Health Sciences 8(Suppl 1):S1-4.

Antonovsky, A. 1996. The salutogenic model as a theory to guide health promotion. Health Promotion International 11(1):11-18. http://dx.doi.org/10.1093/heapro/11.1.11

Bonanno, G. A. 2012. Uses and abuses of the resilience construct: loss, trauma, and health-related adversities. Social Science \& Medicine 74:753-756. http://dx.doi.org/10.1016/j.socscimed.2011.11.022

Corcoran, J., and O. Hughes (editors). 2012. Fiji locally-managed marine area network, Fiji. Equator Initiative Case Studies. Equator Initiative, Environment and Energy Group, United Nations Development Programme, New York, New York, USA.

Folke, C., S. R. Carpenter, B. Walker, M. Scheffer, T. Chapin, and J. Rockström. 2010. Resilience thinking: integrating resilience, adaptability and transformability. Ecology and Society 15(4):20. [online] URL: http://www.ecologyandsociety.org/vol15/iss4/ art20/

Gunderson, L., A. Kinzig, A. Quinland, B. Walker, G. Cundhill, C. Beier, B. Crona, and Ö. Bodin. 2010. Assessing resilience in social-ecological systems: workbook for practitioners. Revised version 2.0. Resilience Alliance.

Rotarangi, S. J., and J. Stephenson. 2014. Resilience pivots: stability and identity in a social-ecological-cultural system. Ecology and Society 19(1):28. http://dx.doi.org/10.5751/ es-06262-190128

Rumbach, A., and D. Foley. 2014. Indigenous institutions and their role in disaster risk reduction and resilience: evidence from the 2009 tsunami in American Samoa. Ecology and Society 19 (1):19. http://dx.doi.org/10.5751/ES-06189-190119

Southwick, S. M., and D. S. Charney. 2012. The science of resilience: implications for the treatment and prevention of depression. Science 338:79-82. http://dx.doi.org/10.1126/science.1222942

Strauch, A. M., J. M. Muller, and A. M. Almedom. 2008. Exploring the dynamics of social-ecological resilience in East and West Africa: preliminary evidence from Tanzania and Niger. African Health Sciences 8(S):28-32.

Suh, H. A. (editor). 2005. Leonardo's notebooks. Writing and art of the great master. Black Dog and Levanthal Publishers, New York, New York, USA.

Walker, B. H., and D. Salt. 2006. Resilience thinking: sustaining ecosystems and people in a changing world. Island Press, Washington, D.C., USA.

Walker, B. H,. and D. Salt. 2012. Resilience practice: building capacity to absorb disturbance and maintain function. Island Press, Washington, D.C., USA. http://dx.doi.org/10.5822/978-1-61091-231-0
Zraly, M., and L. Nyirazinyoye. 2010. Don't let the suffering make you fade away: an ethnographic study of resilience among survivors of genocide-rape in southern Rwanda. Social Science \& Medicine 70:1656-1664. 